\title{
Hyponatremia, IL-6, and SARS-CoV-2 (COVID-19) infection: may all fit together?
}

\author{
A. Berni ${ }^{1}$ (D) D. Malandrino ${ }^{2} \cdot$ G. Parenti ${ }^{3} \cdot$ M. Maggi ${ }^{4,5} \cdot$ L. Poggesi $^{2} \cdot$ A. Peri ${ }^{3,4}$
}

Received: 30 April 2020 / Accepted: 15 May 2020 / Published online: 25 May 2020

(C) Italian Society of Endocrinology (SIE) 2020

Keywords Hyponatremia $\cdot \mathrm{COVID}-19 \cdot$ Interleukin-6 (IL-6) $\cdot \mathrm{PaO}_{2} / \mathrm{FiO}_{2}$ ratio $\cdot$ Tocilizumab

Hyponatremia is the most common electrolyte disorder encountered in clinical practice and is associated with an increased risk of overall mortality in in-patients [1]. The most common cause of hyponatremia is the syndrome of inappropriate antidiuresis (SIAD), which accounts for up to $40-50 \%$ of cases, but the prevalence may be higher in some pathological conditions, such as subarachnoid haemorrhage, traumatic brain injury, and pneumonia [2]. Besides infectious diseases, several inflammatory conditions may be complicated by SIAD. In these situations, interleukin-6 (IL-6), released by monocytes and macrophages, plays a pathogenic role in causing electrolyte impairment by inducing the nonosmotic release of vasopressin [3].

Respiratory failure from acute respiratory distress syndrome (ARDS) is the leading cause of mortality in COVID19 infection, but a secondary hyper-inflammation syndrome characterized by massive release of cytokines may contribute to fatal outcome, determining multiple organ failure [4]. IL-6 is one of the most important cytokines involved in COVID-19-induced pathology. Based on these data, tocilizumab, a humanized monoclonal antibody against the IL-6

A. Peri

alessandro.peri@unifi.it

1 Internal Medicine Unit 3, Careggi University Hospital, Florence, Italy

2 Department of Experimental and Clinical Medicine, University of Florence, Careggi University Hospital, Florence, Italy

3 Pituitary Diseases and Sodium Alterations Unit, Endocrinology, Careggi University Hospital, Florence, Italy

4 Endocrinology, Department of Experimental and Clinical Biomedical Sciences "Mario Serio", University of Florence, Careggi University Hospital, 50139 Florence, Italy

5 Consorzio I.N.B.B., 00136 Rome, Italy receptor, has demonstrated clinical efficacy in the treatment of seriously ill patients [5].

To evaluate the clinical impact of hyponatremia and its correlation with IL-6 levels, we retrospectively evaluated data from 52 laboratory-confirmed COVID-19 patients admitted from March 23, to April 22, 2020, at an Internal Medicine Ward of Careggi University Hospital, completely transformed into a COVID-19 Unit. Among the 52 patients, we excluded those who were pregnant $(n=1)$ or had, at admission, diarrhea $(n=4)$, acute renal failure $(n=8)$ or malignancy $(n=10)$.

Overall, 29 patients were included and divided into two groups: patients with a serum IL-6 level $\leq 10 \mathrm{pg} / \mathrm{mL}$ (the upper normal limit for the hospital lab, Invitrogen Termofisher Scientific) ( $n=12$, group 1) and patients with serum IL-6 level $>10 \mathrm{pg} / \mathrm{mL}(n=17$, group 2$)$. We compared median age, gender, serum sodium concentration $\left(\left[\mathrm{Na}^{+}\right]\right)$, and $\mathrm{PaO}_{2} / \mathrm{FiO}_{2}(P / F)$ ratio at admission.

The lowest $\left[\mathrm{Na}^{+}\right]$detected was $128 \mathrm{mEq} / \mathrm{L}$ (range $128-145 \mathrm{mEq} / \mathrm{L}) \cdot\left[\mathrm{Na}^{+}\right]$and $P / F$ ratio were significantly lower in group $2(133.1 \pm 3.5$ vs $139.6 \pm 2.4, p<0.0001$; $248 \pm 88$ vs $350 \pm 69, p=0.002$, respectively, mean \pm SD) (Fig. 1A). The median age was higher in group 2 patients $(69.5 \pm 14.4$ vs $58.6 \pm 13.9$ years, mean $\pm \mathrm{SD}, p=0.05)$. Male (M) and female (F) gender was equally distributed in the two groups (9 $\mathrm{M}$ and $3 \mathrm{~F}$ in group 1; $12 \mathrm{M}$ and $5 \mathrm{~F}$ in group 2).

IL-6 was inversely correlated with $\left[\mathrm{Na}^{+}\right]$, whereas $\left[\mathrm{Na}^{+}\right]$ was directly correlated with $P / F$ ratio (Pearson's correlation test; Fig. 1B, C, respectively). The bivariate linear regression analysis showed that IL-6 and $\left[\mathrm{Na}^{+}\right]$were independently related to the $P / F$ ratio (respectively, Beta $=-0.45$, $p=0.016$; Beta $=0.33, p=0.048$ ).

Furthermore, hyponatremia was associated with a more severe outcome (i.e., ICU transfer, NIV, death) at Fisher's exact test analysis $(53 \%$ vs $7 \%, p=0.031)$. This association 
Fig. 1 A Serum sodium concentration (Na) and $\mathrm{PaO}_{2} / \mathrm{FiO}_{2}$ ratio $(\mathrm{P} / \mathrm{F}$ ratio $)$ at admission in patients with serum IL-6 level

$<10$ and $>10 \mathrm{pg} / \mathrm{mL}$; B Inverse correlation between serum IL-6 level (IL-6) and serum sodium concentration (Na); C Direct correlation between serum sodium concentration $(\mathrm{Na})$ and $\mathrm{PaO}_{2} / \mathrm{FiO}_{2}$ ratio (P/F ratio) at admission; D Comparison between serum sodium concentration $(\mathrm{Na})$ at admission and after 48 hours in patients with hyponatremia, treated or not (control) with tocilizumab
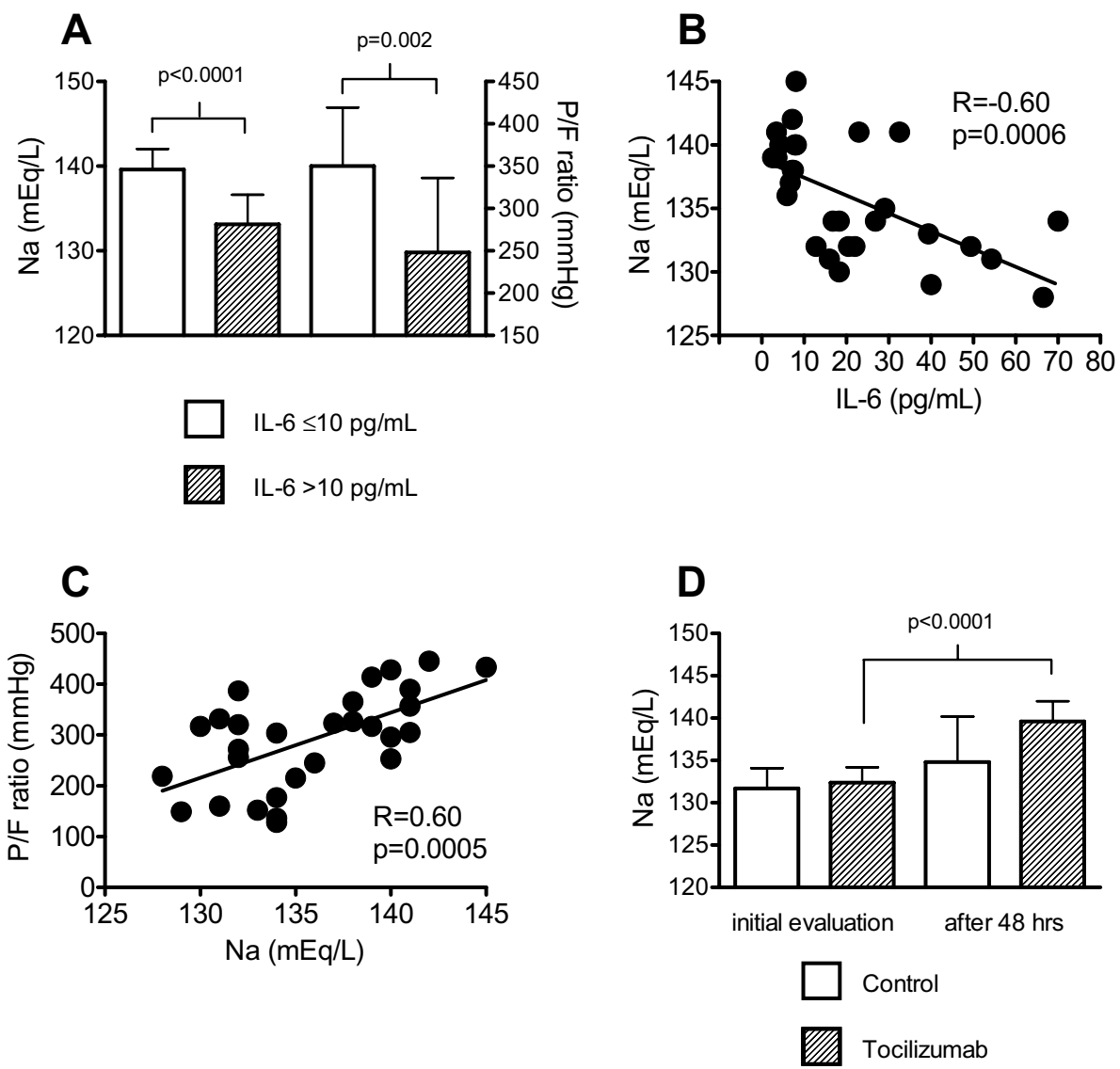

was confirmed by logistic regression analysis $(\mathrm{OR}=14.8$, 95\% CI 1.5 $\pm 144.2, p=0.02$ ).

Among patients with hyponatremia at initial evaluation ( $n=15)$, eight patients with abnormal IL-6 levels and rapid deterioration of respiratory functions were treated with an i.v. double dose of tocilizumab $(8 \mathrm{mg} / \mathrm{kg}$; maximum dose $800 \mathrm{mg}$ ). No significant $\left[\mathrm{Na}^{+}\right]$changes were observed at $48 \mathrm{~h}$ in patients who did not receive tocilizumab administration. Conversely, tocilizumab administration in hyponatremic patients with abnormal IL-6 levels was associated with a significant increase of $\left[\mathrm{Na}^{+}\right]$at $48 \mathrm{~h}(139.6 \pm 2.4 \mathrm{vs}$ $132.4 \pm 1.8 \mathrm{mEq} / \mathrm{L}$, mean $\pm \mathrm{SD}, p<0.0001$; Fig. 1D).

Admittedly, the series of patients reported here is limited, but it has to be considered that a number of patients had to be excluded from the analysis because of the presence of co-morbidities, which may be expected even in large series of COVID-19 patients. However, based on these original observations, we suggest that $\left[\mathrm{Na}^{+}\right]$might represent a readily available biomarker to be considered in the clinical protocols designed for COVID-19 patients. Low $\left[\mathrm{Na}^{+}\right]$appears to be inversely related to IL-6 and directly related to $P / F$ ratio, an important index of respiratory performance. $\left[\mathrm{Na}^{+}\right]$measurements may be rapidly obtained by the lab or even promptly by hemogasanalysis, and definitively earlier than IL-6. Low $\left[\mathrm{Na}^{+}\right]$ appears to be associated with a more unfavourable outcome and it may be hypothesized that $\left[\mathrm{Na}^{+}\right]$decrease indicates the presence of a more advanced disease. The significant increase of $\left[\mathrm{Na}^{+}\right]$after $48 \mathrm{~h}$ from the initiation of tocilizumab treatment further suggests the presence of an association between IL-6, vasopressin release and ultimately $\left[\mathrm{Na}^{+}\right]$itself. $\left[\mathrm{Na}^{+}\right]$ is not currently considered among the inclusion criteria for initiating tocilizumab treatment. However, the right timing of administration might be of pivotal importance in determining the effectiveness of tocilizumab and we hypothesize that $\left[\mathrm{Na}^{+}\right]$ might be of help in decision-making strategies.

In conclusion, we feel that the findings presented here, although preliminary, might be of interest for stimulating prompt and extensive further evaluation by the scientific community.

\section{Compliance with ethical standards}

Conflict of interest On behalf of all authors, the corresponding author states that there is no conflict of interest.

Research involving human participants and/or animals This study contains retrospective data and therefore does not need a formal approval by the local Ethical Committee. The data that are reported in the manu- 
script are included in the routine evaluation of Covid-19 patients performed by the Careggi University Hospital.

Informed consent Informed consent was obtained by patients at the time of hospital admission.

\section{References}

1. Corona G, Giuliani C, Parenti G et al (2013) Moderate hyponatremia is associated with increased risk of mortality: evidence from a meta-analysis. PLoS ONE 8:e80451

2. Cuesta M, Thompson CJ (2016) The syndrome of inappropriate antidiuresis (SIAD). Best Pract Res Clin Endocrinol Metab 30:175-187
3. Hodax JK, Bialo SR, Yalcindag A (2018) SIADH in systemic JIA resolving after treatment with an IL-6 inhibitor. Am Acad Pediatrics 141:e20164174

4. Park M, Cook AR, Lim JT, Sun Y, Dickens BL (2020) A systematic review of COVID-19 epidemiology based on current evidence. J Clin Med 9:967

5. Luo P, Liu Y, Qiu L, Liu X, Liu D, Li J (2020) Tocilizumab treatment in COVID-19: a single center experience. J Med Vir. https ://doi.org/10.1002/jmv.25801

Publisher's Note Springer Nature remains neutral with regard to jurisdictional claims in published maps and institutional affiliations. 